J. Dairy Sci. 91:4661-4672

doi:10.3168/jds.2007-0835

(c) American Dairy Science Association, 2008.

\title{
Comparison of Reticular and Rectal Core Body Temperatures in Lactating Dairy Cows
}

\author{
J. M. Bewley, ${ }^{1}$ M. E. Einstein, M. W. Grott, and M. M. Schutz \\ Department of Animal Sciences, Purdue University, West Lafayette, IN 47907
}

\begin{abstract}
The Phase IV Cattle Temperature Monitoring System (CTMS; Phase IV Engineering Inc., Boulder, CO) marketed by MaGiiX (MaGiiX Inc., Post Falls, ID) uses a passive bolus equipped with a temperature sensor, a panel reader placed at a parlor entrance or exit to query the bolus, and a software package to collect, analyze, and view data. The biologically inert bolus resides in the cow's reticulum and is queried each time the cow passes the reader. Reticular temperature (RETT) and rectal temperature (RECT) were recorded simultaneously in the milking parlor exit lane in 4 consecutive milkings in each of 4 seasons, totaling 16 measurements per cow. The RETT were obtained by using the phase IV CTMS, whereas the RECT were obtained manually with a GLA M750 thermometer (GLA Agricultural Electronics, San Luis Obispo, CA). Data were edited to remove RETT likely to have been affected by a recent drinking bout. For the 2,042 observations used in analyses, means $( \pm \mathrm{SD})$ were $39.28( \pm 0.41), 38.83( \pm 0.36)$, and $0.45( \pm 0.33)$ for RETT, RECT, and the difference between RETT and RECT, respectively. The RETT and RECT were strongly correlated $(\mathrm{r}=0.645)$. The relationship between RETT and RECT varied by season, milking, housing system, and parity. Because dairy producers and veterinarians are accustomed to viewing rectal temperatures, equations to adjust reticular temperatures to a rectal-based scale may increase the utility of the phase IV CTMS. The resulting conversion equations were $\mathrm{RECT}=19.23+0.496(\mathrm{RETT})$ for the a.m. milking and RECT $=15.88+0.587$ (RETT) for the p.m. milking.
\end{abstract}

Key words: biosensor, reticular temperature, rectal temperature, temperature monitoring

\section{INTRODUCTION}

Automatic monitoring of core body temperature in dairy cattle could be useful for the identification of

Received November 5, 2007

Accepted July 21, 2008.

${ }^{1}$ Corresponding author: jbewley@uky.edu illness, heat stress, general physiological stress, and estrus (Fordham et al., 1988; Hicks et al., 2001; Prendiville et al., 2002). Firk et al. (2002) suggested that the utility of a temperature monitor is very dependent on its anatomical location. Attempts to measure the body temperature of cattle have been made at various locations, including the rectum, ear (tympanic), vagina, reticulorumen, intraperitoneal cavity, and udder (milk). Manual collection of rectal temperatures is the most common method of obtaining body temperatures in practice because of the ease of measurement and low purchase costs of rectal thermometers (Hicks et al., 2001; Aalseth, 2005). However, the accuracy of rectal thermometers is affected by the competency of the operator using them. This process is also labor intensive, time consuming, and may result in rectal injuries. Furthermore, because restraining animals to collect temperature data by manual means may cause stress that alters temperature, a reliable method of collecting temperatures without human intervention is likely to provide a more accurate measure of temperature in dairy cattle (Hahn et al., 1990; Prendiville et al., 2002).

Sievers et al. (2004) suggested that an intraruminal measuring system would be advantageous because it is independent of external disturbing factors, cannot be manipulated from the outside, and is less likely to be lost. Rumen temperatures have been established as effective measures of core body temperature (Hicks et al., 2001; Prendiville et al., 2002). Because of the activity of heat-producing rumen microorganisms, ruminal or reticular temperatures are generally approximately $0.5^{\circ} \mathrm{C}$ greater than core body temperatures (Bitman et al., 1984; Hicks et al., 2001; Prendiville et al., 2002). Missouri researchers found ruminal temperatures to be $0.71^{\circ} \mathrm{C}$ (shade) and $0.49^{\circ} \mathrm{C}$ (no shade) greater than intraperitoneal temperatures, although no differences were observed when ambient temperatures increased above $25^{\circ} \mathrm{C}$ (McVicker et al., 2001). Prendiville et al. (2002) compared temperature readings from Cow Temp (Innotek Inc., Garrett, IN) rumen boluses, tympanic telemetry transmitters, and rectal temperatures taken hourly. The averages for the 5 -d period studied were $39.0,38.4$, and $38.2^{\circ} \mathrm{C}$ for rumen, rectal, and tympanic 
temperatures, respectively. Sievers et al. (2004) showed highly significant correlations between intraruminal and rectal temperatures $(\mathrm{r}=0.92)$ based on 36 observations.

Before this work, research examining the relationship between reticular temperatures (RETT) and rectal temperatures (RECT) was largely limited to a small number of animals measured over short time frames. With the availability of a commercially produced temperature bolus, this research was designed to assess the dynamics of the relationship between these 2 temperature measures across an entire herd of cows in varying environmental conditions. A secondary objective of this study was to develop an equation to convert RETT to a scale based on RECT more familiar to producers and veterinary practitioners.

\section{MATERIALS AND METHODS}

\section{Data Collection}

This research was conducted at the Purdue Dairy Research and Education Center (West Lafayette, IN). Cows were managed in 3 housing systems: a free-stall barn (FS) with 128 stalls in 4 quadrants, a bedded-pack barn with an open grass lot (BP), and a geothermally modified barn with tie stalls for overflow and sick cows and box stalls for recently fresh cows (GM). Care and use of the cows was approved by the Purdue Animal Care and Use Committee.

Reticular temperatures were collected by using the Phase IV Cattle Temperature Monitoring System (CTMS, Phase IV Engineering Inc., Boulder, CO) marketed by MaGiiX (MaGiiX Inc., Post Falls, ID). Each cow was equipped with a Phase IV bolus, a passive radio-frequency transponder permanently residing in the cow's reticulum. The bolus contains temperature measuring electronics. When the animal passes a stationary panel reader, radar motion sensors detect the animal, which turns on the transmitter. A magnetic field then induces an electrical charge inside the bolus, energizing the transmitter. In response to this interrogation signal, the bolus responds by transmitting its unique identification number and temperature on a coded radio frequency. This information is then transmitted to an on-site computer and later to a server, allowing simple on-line viewing and downloading for further analysis. Rectal temperatures were recorded by using a GLA M750 digital thermometer (GLA Agricultural Electronics, San Luis Obispo, CA), transmitted via a USB cable to a laptop computer, and recorded manually for verification.

General cow demographic information was obtained from PCDart (Dairy Records Management Systems,

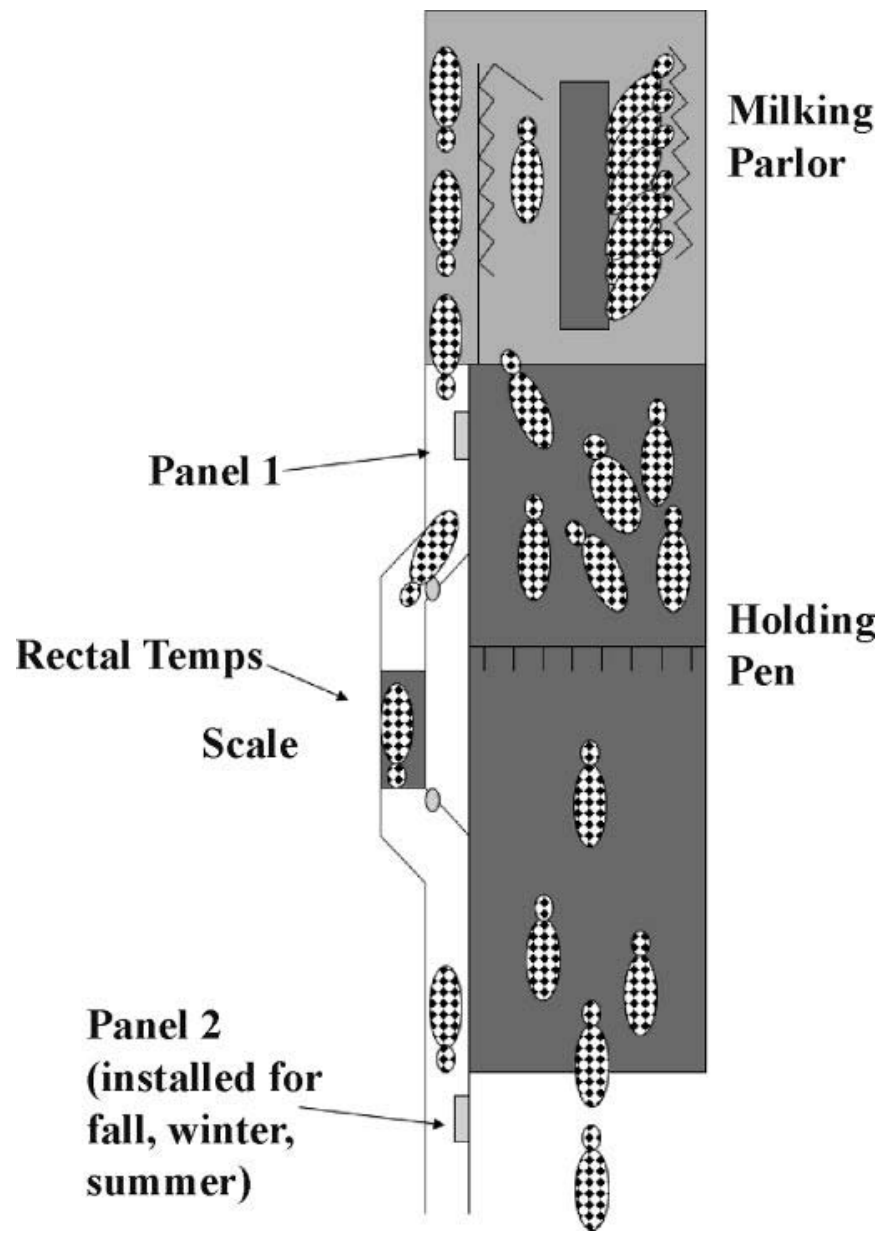

Figure 1. Layout of temperature collection area.

Raleigh, NC) records. Daily milk weights and times were recorded by using the Alpro system (DeLaval Inc., Kansas City, MO). Ambient weather conditions were recorded at 0.5 -h intervals at the Purdue Agronomy Research Farm, which is adjacent to the Purdue Dairy Research and Education Center. Temperature-humidity index (THI) was computed by using the following formula (NOAA, 1976): THI = temperature $\left({ }^{\circ} \mathrm{F}\right)-[0.55$ $-(0.55 \times$ relative humidity $/ 100)] \times\left[\right.$ temperature $\left({ }^{\circ} \mathrm{F}\right)$ -58.8 . Maximum and average THI for each day were calculated at the last recorded time for a given day $(2330 \mathrm{~h})$, using information from the previous $24 \mathrm{~h}$.

Temperatures were collected for every lactating Holstein cow for 4 consecutive milkings each during 4 collection periods selected to represent varying environmental conditions. The 4 collections were conducted on May 30 and 31, 2006 (spring), September 27 and 28, 2006 (fall), January 31 and February 1, 2007 (winter), and July 25 and 26, 2007 (summer). The numbers of cows sampled during each collection period were 185, 187, 180, and 182 for spring, fall, winter, and summer, 
respectively. Because of herd turnover and dry periods, 280 total cows were utilized across the entire study period. The RECT were collected by the same operator for the spring, winter, and summer collection periods, with a different operator collecting temperatures for the fall collection period. During the spring, winter, and summer collection periods, the order of milking among housing systems was (1) FS, (2) BP, and (3) GM. In the fall collection period, the order of milking was (1) GM, (2) FS, and (3) BP. All temperatures were recorded immediately after milking. Milking times were between 0500 and $0930 \mathrm{~h}$ for the a.m. milking and between 1600 and $2230 \mathrm{~h}$ for the p.m. milking.

The first reader panel was located in a single-lane exit alley from the milking parlor (Figure 1). After cows passed the first reader panel, they were diverted into a stationary scale, where RECT were collected. Cows were moved at a steady pace, and RECT were collected continuously to minimize slowing the milking process and the time between collection of RETT and RECT. After collection of RECT, cows passed a second reader panel located in a pathway leading to the freestall barn. This second panel was added only after the spring collection period (and was thus available for the fall, winter, and summer collection periods) to increase the percentage of cows passing the panel with a valid RETT reading. Adding a second panel proved beneficial by increasing the likelihood that a cow's temperature was measured at 1 of the 2 panels. Both panels used the same technology to read boluses and were close in proximity; consequently, variation in temperatures between panels was not a concern.

\section{Editing RETT}

The RETT were collected as part of a longer term project (June 2006 to August 2007) examining how changes in temperature reflected physiological events of interest (i.e., illness and estrus; our unpublished data). The unedited data set contained 237,395 temperature readings from lactating Holstein and Brown Swiss cows. The following edits were performed on this large data set before combining RETT for the 4 collection periods with RECT. First, readings from 9 boluses were discarded $(\mathrm{n}=6,801)$ because of consistently low readings (e.g., $10^{\circ} \mathrm{C}$ ). All RETT less than $35.6^{\circ} \mathrm{C}$ or greater than $42.2^{\circ} \mathrm{C}$ were then deleted $(\mathrm{n}=567)$ because temperatures in these extremes were assumed to represent infrequent bolus errors rather than the physiological status of the cow being monitored.

Because water intake can elicit a dramatic decrease in RETT for as long as $3.5 \mathrm{~h}$ (Bewley et al., 2007), additional edits were performed to eliminate readings likely affected by a recent drinking bout. Generally, with temperatures recorded in the exit lane and no water available in the holding pen or parlor, cows would not have had access to water for 30 to 60 min before the temperature measurement. Because of an increased likelihood of a recent drinking bout, all readings not associated with a milking were removed $(\mathrm{n}=4,338)$. These readings occurred when the cow passed the reader panel because of movement related to other research projects or management events.

The exit lane and the first reader panel were adjacent to the holding pen, allowing some temperatures to be recorded while cows were in the holding pen before milking. To eliminate this concern, the time of the recorded temperature was compared with the time of the recorded milking and all temperature readings before milking were removed $(\mathrm{n}=32917)$. The large number of reads removed with this edit is a result of cows standing by the panel for an extended period, resulting in a series of repeated readings (e.g., 30 to 40) on the same cow.

With 2 panels, within-milking repeated readings occurred frequently. To maximize the amount of time since the cow had access to water, all temperature readings except for the last reading for each cow during a given milking were deleted $(\mathrm{n}=68,806)$. The mean $\left(39.22^{\circ} \mathrm{C}\right)$ and $\mathrm{SD}(0.47)$ of the remaining 123,966 observations were used to remove any temperature $(\mathrm{n}=$ $861)$ less than 3 standard deviations $\left(<37.81^{\circ} \mathrm{C}\right)$ from the overall mean. Last, a 2-wk within-milking rolling average RETT and standard deviation were calculated for each cow. Any temperature less than 3 standard deviations from the cow's rolling average was removed $(\mathrm{n}=148)$. Each of these edits was performed with the goal of removing low temperatures deviating from the expected temperature that were believed to have been influenced by a recent drinking bout. The final edited data set included 122,957 observations.

\section{Pairing of RETT and RECT}

The RETT from the edited data set were paired within milking with RECT for the $8 \mathrm{~d}$ when both were recorded simultaneously. Only observations from Holstein cows (Brown Swiss cows were not included in the analysis) with both RETT and RECT available ( $\mathrm{n}=$ 2137) were retained for analysis. If the cow defecated during collection of her RECT, this occurrence was noted and these paired observations were discarded (n $=88$ ), because RECT increased notably during and after defecation. Means and standard deviations were calculated for RETT, RECT, and the difference between paired temperatures (TDIF). If TDIF was greater than \pm 3 standard deviations from the overall mean difference and either RETT or RECT was greater than 
\pm 3 standard deviations from their respective means, the observation was deleted. This edit removed 7 paired observations, leaving 2,105 observations for remaining analyses.

\section{Data Analysis}

Pearson correlation coefficients were calculated to compare paired RETT and RECT by using PROC CORR (SAS Institute Inc., Cary, NC) for all observations, and by season, milking, breed, and housing system. The PROC MIXED of SAS was used to fit models to describe TDIF, RETT, and RECT. Random effects were included in the models when significant at $P<$ 0.10. Fixed effects for season (spring, fall, winter, or summer), milking (a.m. or p.m.), housing system (freestall, tie-stall, or loose housing), and parity ( 1 or $\geq 2$ ) and covariables for DIM and milk weight, along with 2- and 3-way interactions, were included in each model. All main effects were kept in each model, regardless of significance level. Only interactions significant at $P \leq 0.10$ were included in the models reported here; however, lower order interactions were kept if they were contained in significant higher order interactions, even if the lower order interactions were not significant.

These mixed models were defined as:

$$
\begin{aligned}
& \mathrm{y}_{\mathrm{ijklmn}}=\mu+\operatorname{Cow}(\mathrm{SE} \times \mathrm{HS} \times \mathrm{PA})_{\mathrm{i}}+\mathrm{SE}_{\mathrm{j}}+\mathrm{MI}_{\mathrm{k}} \\
& +\mathrm{HS}_{1}+\mathrm{PA}_{\mathrm{m}}+(\mathrm{SE} \times \mathrm{MI})_{\mathrm{jk}}+(\mathrm{SE} \times \mathrm{HS})_{\mathrm{j} 1}+(\mathrm{MI} \\
& \times \mathrm{HS})_{\mathrm{kl}}+(\mathrm{SE} \times \mathrm{PA})_{\mathrm{jm}}+(\mathrm{HS} \times \mathrm{PA})_{\mathrm{lm}}+(\mathrm{SE} \times \mathrm{HS} \\
& \times \mathrm{PA})_{\mathrm{jlm}}+(\mathrm{SE} \times \mathrm{MI} \times \mathrm{HS})_{\mathrm{jkl}}+\beta_{1} \mathrm{DIM}_{\mathrm{ijk} \mathrm{m} n} \\
& +\beta_{2} \mathrm{MW}_{\mathrm{ijklmn}}+\beta_{3}\left(\mathrm{MW}_{\mathrm{ijklmn}} \times \mathrm{DIM}_{\mathrm{ijklmn}}\right) \\
& +\beta_{4, \mathrm{l}}\left(\mathrm{MW}_{\mathrm{ijklmn}} \times \mathrm{HS}_{\mathrm{l}}\right)+\beta_{5, \mathrm{~m}}\left(\mathrm{MW}_{\mathrm{ijklmn}} \times \mathrm{PA}_{\mathrm{m}}\right) \\
& +\beta_{6, \mathrm{j}}\left(\mathrm{DIM}_{\mathrm{ijk} k \mathrm{mn}} \times \mathrm{SE}_{\mathrm{j}}\right)+\beta_{7, \mathrm{~m}}\left(\mathrm{DIM}_{\mathrm{ijk} k \mathrm{mn}} \times \mathrm{PA}_{\mathrm{m}}\right) \\
& +\beta_{8,1}\left(\mathrm{DIM}_{\mathrm{ijklmn}} \times \mathrm{HS}_{\mathrm{l}}\right)+\beta_{9, \mathrm{j}}\left(\mathrm{MW}_{\mathrm{ijklmn}} \times \mathrm{SE}_{\mathrm{j}}\right) \\
& +\beta_{10, \mathrm{~lm}}\left(\mathrm{MW}_{\mathrm{ijk} k \mathrm{mn}} \times \mathrm{HS}_{1} \times \mathrm{PA}_{\mathrm{m}}\right)+\beta_{11, \mathrm{j}}\left(\mathrm{DIM}_{\mathrm{ijklmn}}\right. \\
& \left.\times \mathrm{MW}_{\mathrm{ijklmn}} \times \mathrm{SE}_{\mathrm{j}}\right)+\beta_{12, \mathrm{~m}}\left(\mathrm{DIM}_{\mathrm{ijklmn}} \times \mathrm{MW}_{\mathrm{ijklmn}}\right. \\
& \left.\times \mathrm{PA}_{\mathrm{m}}\right)+\beta_{13, \mathrm{jm}}\left(\mathrm{DIM}_{\mathrm{ijklmn}} \times \mathrm{SE}_{\mathrm{j}} \times \mathrm{PA}_{\mathrm{m}}\right) \\
& +\beta_{14, \mathrm{jl}}\left(\mathrm{DIM}_{\mathrm{ijklmn}} \times \mathrm{SE}_{\mathrm{j}} \times \mathrm{HS}_{\mathrm{l}}\right)+\mathrm{e}_{\mathrm{ijklmn}},
\end{aligned}
$$

where $\mathrm{y}_{\mathrm{ijklmn}}$ is the nth difference in temperatures, RECT or RETT of cow i in season $\mathrm{j}$ at milking $\mathrm{k}$ in housing system $l$ in parity $\mathrm{m} ; \mu$ is the intercept; $\mathrm{Cow}(\mathrm{SE} \times \mathrm{HS}$ $\times \mathrm{PA})_{\mathrm{i}}$ is the random effect of cow $\mathrm{i}$ within season $\mathrm{j}$, housing system 1 , and parity $\mathrm{m} ; \mathrm{SE}_{\mathrm{j}}, \mathrm{MI}_{\mathrm{k}}, \mathrm{HS}_{\mathrm{l}}, \mathrm{PA}_{\mathrm{m}}$, (SE $\times \mathrm{MI})_{\mathrm{jk}},(\mathrm{SE} \times \mathrm{HS})_{\mathrm{jl}},(\mathrm{MI} \times \mathrm{HS})_{\mathrm{kl}},(\mathrm{SE} \times \mathrm{PA})_{\mathrm{jm}},(\mathrm{HS} \times$ $\mathrm{PA})_{\mathrm{lm}},(\mathrm{SE} \times \mathrm{HS} \times \mathrm{PA})_{\mathrm{jlm}}$, and $(\mathrm{SE} \times \mathrm{MI} \times \mathrm{HS})_{\mathrm{jkl}}$ are fixed effects for season $\mathrm{j}$ ( $\mathrm{j}=1$ to 4 for spring, summer, fall, or winter $)$, milking $\mathrm{k}(1=\mathrm{a} . \mathrm{m}$. or $2=$ p.m. $)$, housing system 1 ( $1=$ free stall, $2=$ bedded pack, or $3=$ other stalls), parity $\mathrm{m}(1=$ parity 1 , or $2=$ parity $\geq 2)$, respectively, along with associated interactions: $\beta_{1}, \beta_{2}$, $\beta_{3}, \beta_{4}, \beta_{5}, \beta_{6}, \beta_{7}, \beta_{8}, \beta_{9}, \beta_{10}, \beta_{11}, \beta_{12}, \beta_{13}$, and $\beta_{14}$ are regression coefficients corresponding to the covariables DIM $\left(\mathrm{DIM}_{\mathrm{ijklmn}}\right)$ and milk weight $\left(\mathrm{MW}_{\mathrm{ijklmn}}\right)$, respectively, along with associated interactions; and $\mathrm{e}_{\mathrm{ijklmn}}$ is residual error.

Similarly, PROC MIXED of SAS was used to fit models for prediction of RECT from RETT. In the simple prediction model to allow conversion of RETT to the more familiar RECT, RETT, milking, and their interaction were the only independent variables considered, with the intention of creating a usable conversion equation for interpretation of reticular temperatures on a more familiar rectal temperature scale. For the full conversion model, all fixed effects were as in model 1 except that the linear effect of RETT and the interactions of RETT were included as independent variables. Finally, predicted RETT and RECT were compared graphically with DIM and milk yield.

\section{RESULTS AND DISCUSSION}

The maximum and average THI for the 8 collection days are presented in Table 1. Although the intention was to test the relationship between RETT and RECT in divergent conditions representative of the 4 seasons, the organization of resources necessitated that collection days were chosen in advance of actual collection. Unfortunately, the ambient conditions did not vary as much as desired. The greatest maximum and average THI were actually observed for the spring collection period, although these THI were only slightly greater than those for the summer collection period. The average and maximum THI for the fall collection period were somewhat lower than for the spring or summer collection period, and these were considerably greater than the winter collection period.

Table 1. Maximum and average temperature-humidity index (THI) for sample day

\begin{tabular}{lcc}
\hline Date & Maximum THI & Average THI \\
\hline May 30, 2006 & 79.22 & 74.13 \\
May 31, 2006 & 77.75 & 70.80 \\
September 27, 2006 & 70.05 & 60.87 \\
September 28, 2006 & 60.32 & 51.41 \\
January 31, 2007 & 30.59 & 20.72 \\
February 1, 2007 & 29.41 & 26.28 \\
July 25, 2007 & 75.67 & 67.75 \\
July 26, 2007 & 77.13 & 70.57 \\
\hline
\end{tabular}




\section{Descriptive Statistics}

Overall means $( \pm \mathrm{SD})$ across all 16 milkings were $39.28^{\circ} \mathrm{C}( \pm 0.42)$ and $38.85( \pm 0.39)$ for RETT ( $\mathrm{n}=$ $2195)$ and RECT $(\mathrm{n}=2797)$, respectively. Assuming that 4 potential temperatures could be collected per collection period for each sampled cow, 740, 748, 720, and 728 observations for both RETT and RECT were possible for the spring, fall, winter, and summer collection periods, respectively. For RETT, valid temperatures were collected for $47,80,81$, and $90 \%$ of potential observations for the spring, fall, winter, and summer collection periods, respectively. Clearly, adding the second reader panel after the spring collection period enhanced the reading percentage for the CTMS. For RECT, temperatures were collected for 95, 98, 94, and $94 \%$ of potential observations during the spring, fall, winter, and summer collection periods, respectively. For the 2,042 observations used in all subsequent analyses, means $( \pm \mathrm{SD})$ were $39.28( \pm 0.41), 38.83( \pm 0.36)$, and 0.45 ( \pm 0.33$)$ for RETT, RECT, and TDIF, respectively. As with all previous research, RETT were considerably greater than RECT. The TDIF was greater than that reported by Burns et al. (2002) when using this same technology $\left(0.2\right.$ to $\left.0.3^{\circ} \mathrm{C}\right)$ and lesser than that reported by Prendiville et al. (2002) with the Cow Temp rumen bolus $\left(0.6^{\circ} \mathrm{C}\right)$. Missouri researchers found ruminal temperatures to be $0.71^{\circ} \mathrm{C}$ (shade) and $0.49^{\circ} \mathrm{C}$ (no shade) greater than intraperitoneal temperatures (McVicker et al., 2001). In the study by McVicker et al. (2001), the comparison was with intraperitoneal temperature rather than RECT. These results included a large number of cows in varying environmental conditions, whereas previous research was more limited in scope.

Histograms for the distributions of these 3 variables are depicted in Figure 2. The distribution of RECT was tighter than that of RETT, reflecting less variation among RECT. Previous research has also indicated that rumen temperatures were more variable than RECT (Noffsinger et al., 1961). The RETT may have more variation because of equipment errors, the influence of water intake, more within- or among-animal variation, changes in VFA production within the reticulorumen, greater sensitivity to ambient conditions, or increased ability to detect physiological changes. The TDIF were more widely dispersed than expected. Surprisingly, RECT was greater than RETT for $7.1 \%(\mathrm{n}=143)$ of paired observations, and the 2 temperatures were the same for $2.1 \%(\mathrm{n}=42)$ of paired observations. Different diurnal variations between the 2 locations or individual animal variation may explain why RETT would sometimes be lower than RECT. However, the most likely reason for this unexpected result is measurement error for RETT, RECT, or both for these observations.
Nevertheless, for most paired observations, RETT was between 0 and $0.5(50.0 \%, \mathrm{n}=1,020)$ or 0.5 and $1^{\circ} \mathrm{C}$ $(37.6 \%, \mathrm{n}=767)$ greater than RECT. Last, RETT was more than $1^{\circ} \mathrm{C}$ greater than RECT for $3.4 \%(\mathrm{n}=70)$ observations. The general tendency for greater RETT reflects the increased heat of fermentation produced by bacteria in the reticulorumen.

\section{Correlations}

The overall Pearson correlation coefficient between RETT and RECT for the 2,042 paired observations was $0.645(P<0.0001)$. The TDIF was more closely correlated with RETT $(\mathrm{r}=0.534)$ than with RECT $(\mathrm{r}$ $=-0.299)$. The correlation between RETT and RECT was greater than the correlation $(\mathrm{r}=0.50)$ reported by Burns et al. (2002) when using this same technology in 4 cows around the occurrence of estrus and was greater than that reported by Prendiville et al. (2002) when using the Cow Temp bolus $(r=0.34)$. However, this correlation was considerably lower than that reported $(\mathrm{r}=$ 0.92 ) by Sievers et al. (2004) when using an intraruminal device, but that correlation estimate was based on only 36 observations. Although the correlation in this data set was lower than correlations reported in the literature among temperature measurements at other anatomical locations, it is important to remember that neither should be considered the ideal benchmark for core body temperature. The reticulorumen is limited by the impact of water and feed, whereas the rectum is limited by human error in the depth and duration of probe insertion and the presence of air or feces in the rectum. As a result, any comparison of these 2 methods will reflect these errors on both sides of the equation. Another potential influence on this relationship is that the diurnal variation in RETT and RECT may be different, particularly because of the impact that feed and water intake has on RETT.

Pearson correlation coefficients between RETT and RECT for various categories are presented in Table 2. Correlations were greater for the spring and fall collection periods ( 0.715 and 0.726 , respectively) than for the summer and winter collection periods $(0.580$ and 0.565 , respectively). That the RETT were greatest during the spring and fall collection periods (Figure 3) suggests that the correlation between RETT and RECT was larger when RETT were greater. During the fall collection period, RECT were collected by a different operator than during the other collection periods. This result may simply indicate that the relationship between the 2 temperatures was stronger when environmental conditions had exerted a stronger influence. The correlation between RETT and RECT was greater for the p.m. milking (0.729) than for the a.m. milking (0.547). 
Table 2. Numbers of Pearson correlation coefficients (r) and paired observations (n) between reticular and rectal temperatures between paired observations across categories ${ }^{1}$

\begin{tabular}{lcr}
\hline Item & $\mathrm{r}$ & $\mathrm{n}$ \\
\hline Season & & \\
Spring & 0.715 & 330 \\
Summer & 0.580 & 584 \\
Fall & 0.726 & 573 \\
Winter & 0.565 & 555 \\
Milking & & \\
a.m. & 0.547 & 999 \\
p.m. & 0.729 & 1,043 \\
Housing system & \\
FS & 0.646 & 1,539 \\
GM & 0.758 & 210 \\
BP & 0.576 & 293 \\
\hline
\end{tabular}

${ }^{1} P<0.005$ for $\mathrm{H}_{0}: \mathrm{r} \neq 0$ for all correlations.

${ }^{2}$ Cows were managed in 3 housing systems: a free-stall barn (FS) with 128 stalls in 4 quadrants, a bedded-pack barn with an open grass lot (BP), and a geothermally modified barn with tie stalls for overflow and sick cows and box stalls for recently fresh cows (GM).

Again, this relationship suggests that correlations were greater when RETT were greater. Differences in diurnal variations between the 2 temperatures may have influenced this relationship. Among housing systems, correlations were greatest for cows housed in the GM (0.758), followed by those housed in the FS (0.646) and BP (0.576), respectively. Cows housed in the GM were more likely to be there because they were ill or just fresh. Because these cows would be more apt to fall outside normal ranges of temperature, this observation corresponds to the concept of increasing correlations with deviating body temperatures.

\section{Modeling to Describe Temperatures}

A series of mixed models were fitted to describe RETT, RECT, and TDIF. Model parameters and significant fixed effects are presented in Table 3. Akaike's information criterion and Schwarz's Bayesian criterion were the 2 metrics used to assess the goodness of fit of the model. With both criteria, lower values indicate a better fit. Generally, Akaike's information criterion and Schwarz's Bayesian criterion should not be compared across models. In each of the 3 models, effects of season, milking, housing system, parity, DIM, and milk yield were significant $(P<0.10)$, either through main effects or within interaction terms.

The least squares means for the significant effects in these mixed models are presented in Figures 3, 4, and 5. Differences were considered significant when using a 0.05 significance level with Tukey's adjustment. For RETT, temperatures were significantly greater during the spring and fall collection periods than during the summer and winter collection periods. The RECT for
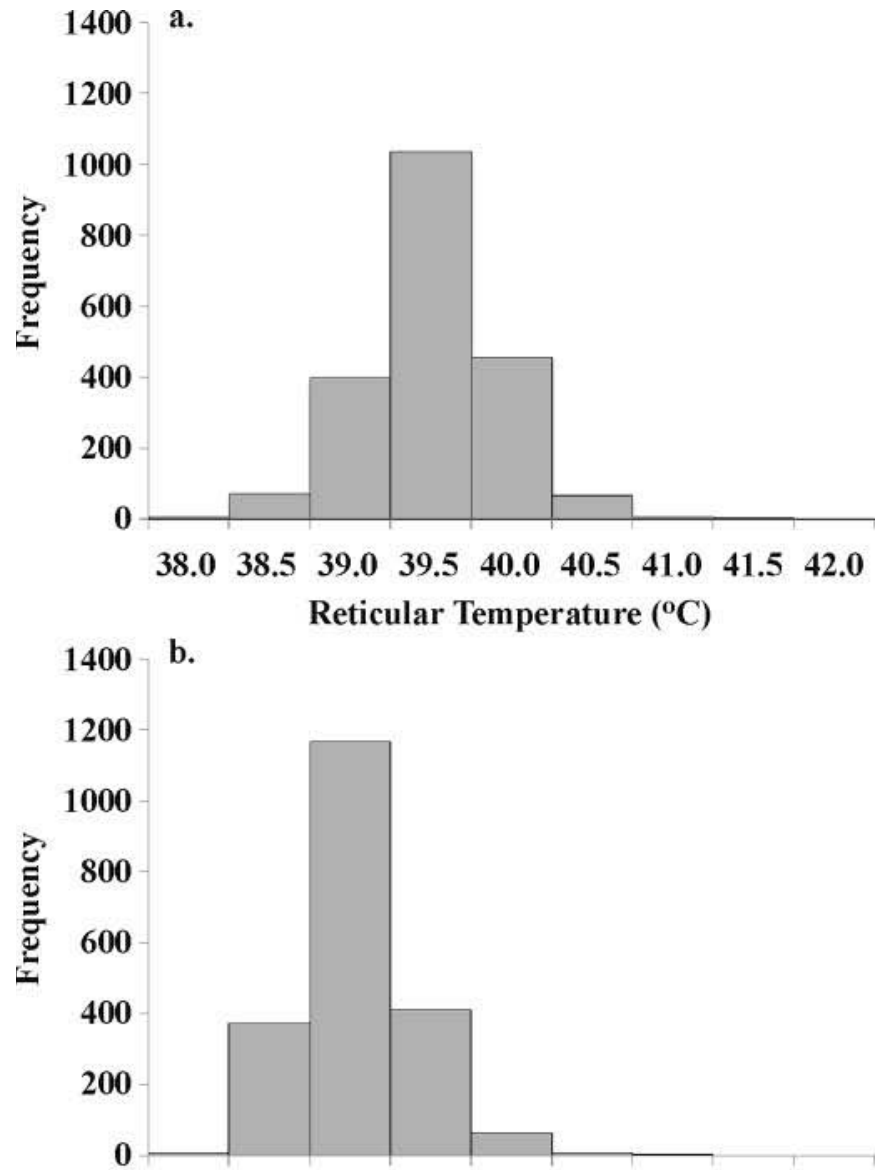

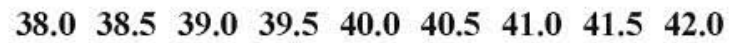
Rectal Temperature $\left({ }^{\circ} \mathrm{C}\right)$

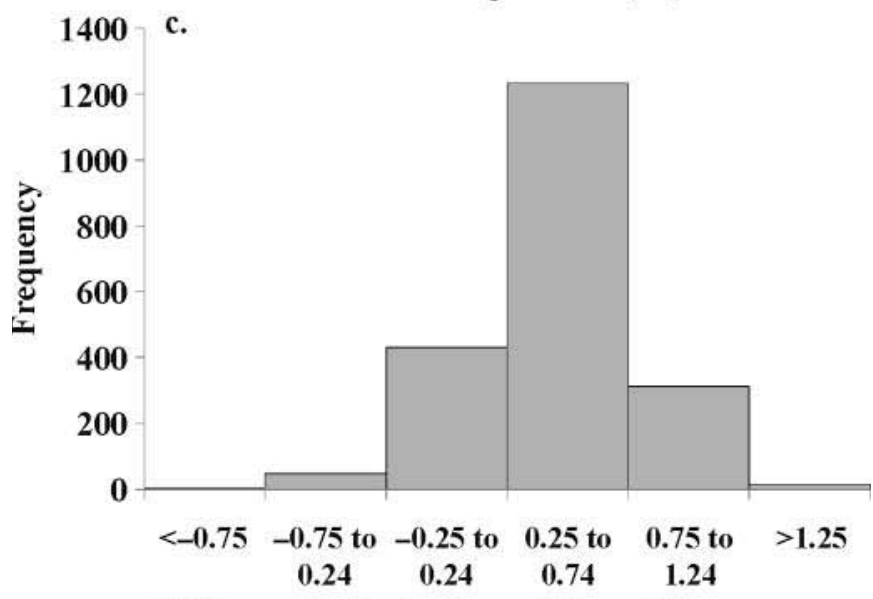

Difference in Reticular and Rectal Temperatures

Figure 2. Frequency histograms of reticular temperature (a), rectal temperature (b), and difference between rectal and reticular temperatures (c; difference calculated by subtracting rectal temperature from reticular temperature). 
Table 3. Model parameters and $P$-values for fixed effects for mixed models describing 2 measures of body temperature

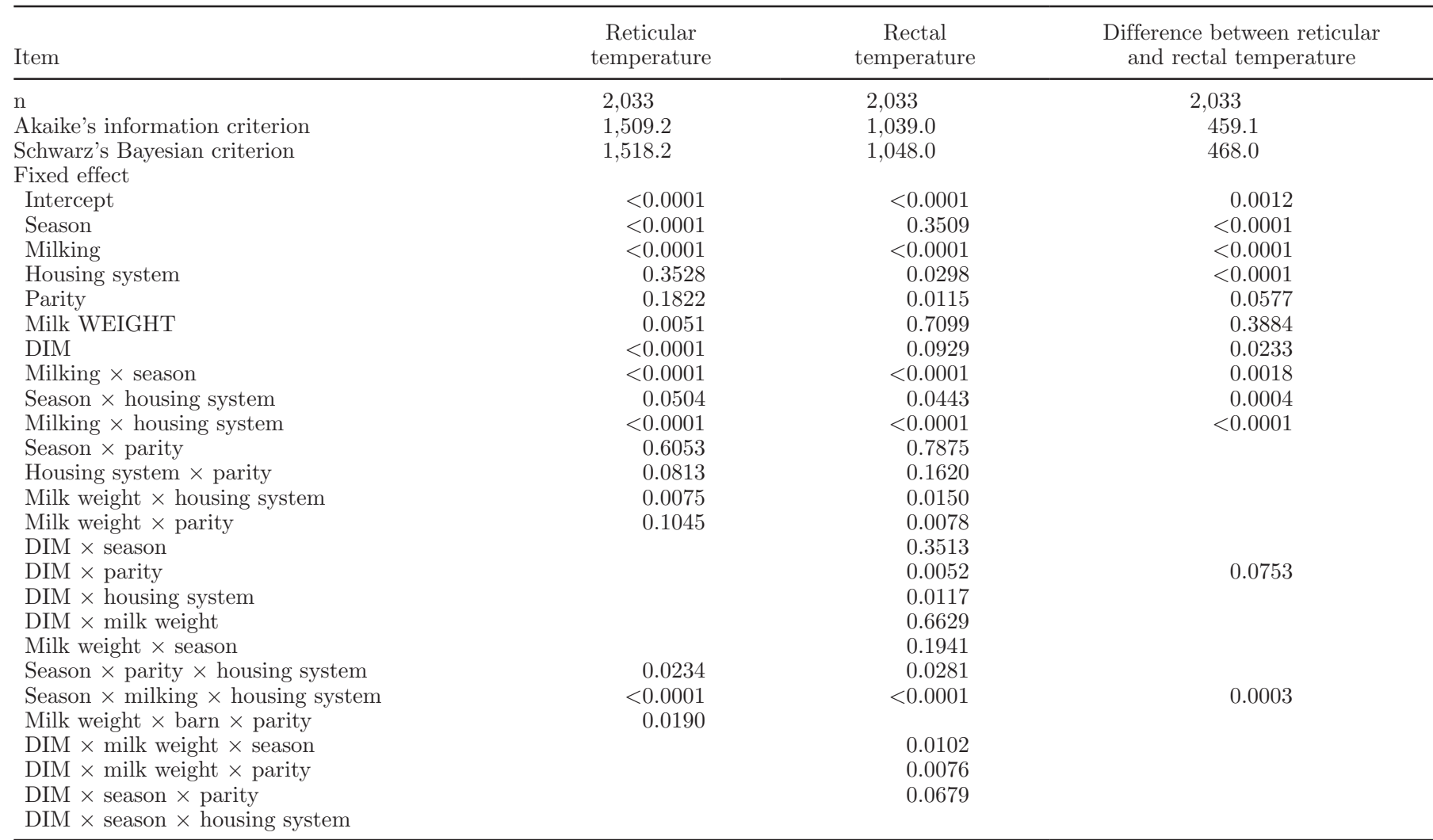

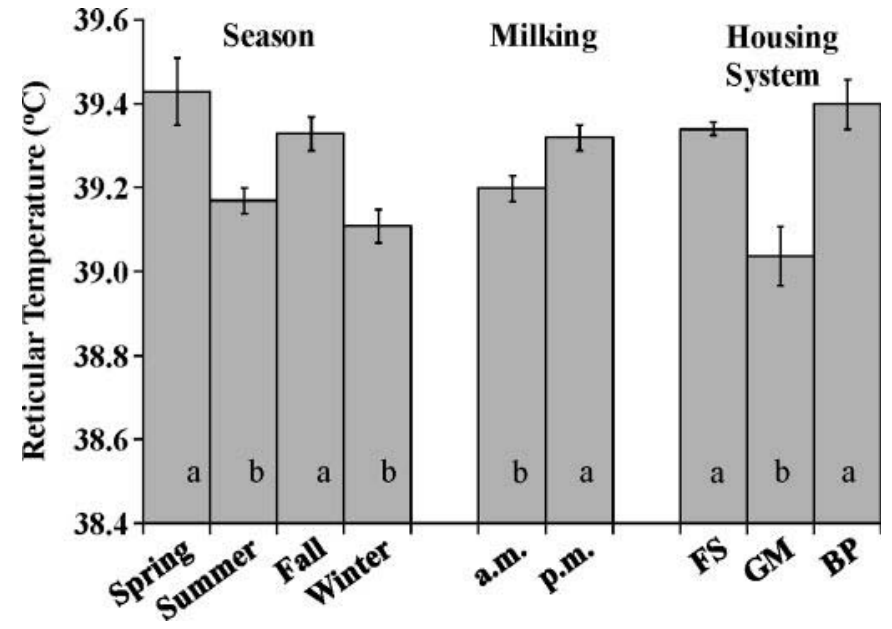

Figure 3. Least squares means for significant fixed effects in mixed models for reticular temperature. Least squares means within category with different letters were significantly different $(P<0.05)$ when using Tukey's adjustment for comparison of means. Cows were managed in 3 housing systems: a free-stall barn (FS) with 128 stalls in 4 quadrants; a bedded-pack barn with an open grass lot (BP); and a geothermally modified barn with tie stalls for overflow and sick cows and box stalls for recently fresh cows (GM).

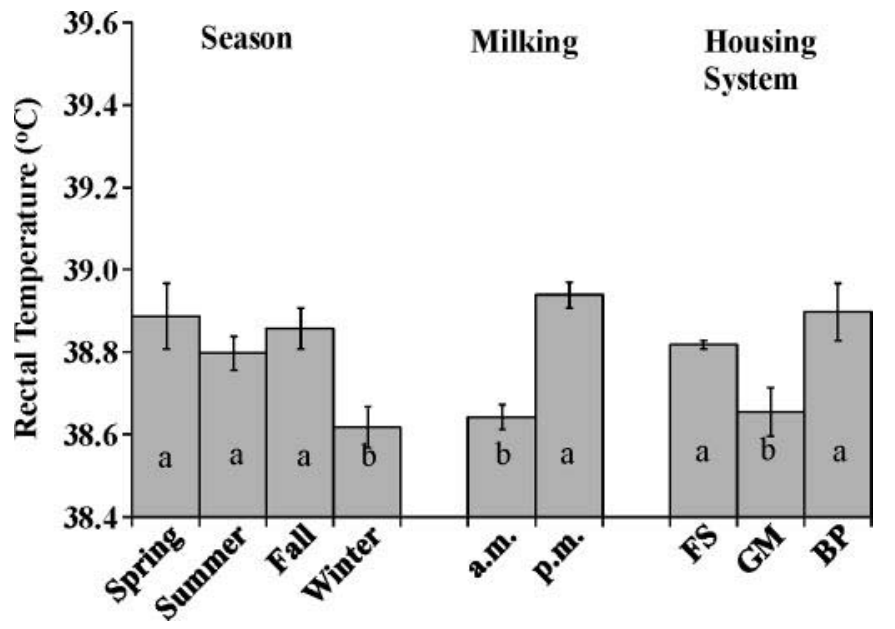

Figure 4. Least squares means for significant fixed effects in mixed models for rectal temperature. Least squares means within category with different letters were significantly different $(P<0.05)$ when using Tukey's adjustment for comparison of means. Cows were managed in 3 housing systems: a free-stall barn (FS) with 128 stalls in 4 quadrants, a bedded-pack barn with an open grass lot (BP), and a geothermally modified barn with tie stalls for overflow and sick cows and box stalls for recently fresh cows (GM). 
winter were significantly lower than for other collection periods; however, all other between-season comparisons were not significantly different. The TDIF was significantly greater for the spring collection period than for the fall and winter collection periods, whereas the TDIF for the fall and winter collection periods was greater than for the summer collection period.

Considering that ambient conditions were fairly similar for the spring, summer, and fall collection periods and considerably lower for the winter collection period, RECT behaved as expected, with the only significant difference being lower RECT during the winter collection period. Conversely, RETT deviated from this expected pattern. Gengler et al. (1970) reported that rumen temperatures were increased significantly with increased ambient temperatures and with intraruminal heating.

Differences in the TDIF closely followed the differences in RETT, with the greatest $\operatorname{TDIF}\left(0.58^{\circ} \mathrm{C}\right)$ observed in the spring and the least TDIF $\left(0.30^{\circ} \mathrm{C}\right)$ observed in the fall. McVicker et al. (2001) also found that the difference between rumen and rectal temperatures increased with increasing ambient temperatures up to $25^{\circ} \mathrm{C}$, after which no differences were observed. Gengler et al. (1970) demonstrated that the difference between rectal and rumen temperatures was greater $(0.37$ vs. $\left.0.09^{\circ} \mathrm{C}\right)$ with lower ambient temperatures $\left(18.2^{\circ} \mathrm{C}, 50 \%\right.$ relative humidity) than with greater ambient temperatures $\left(35^{\circ} \mathrm{C}, 50 \%\right.$ relative humidity). The high ambient temperatures in that research were considerably greater than those in this study.

The depressed RETT and TDIF in the summer collection period may reflect the effectiveness of heat abatement strategies (sprinklers and fans) in the FS barn, although one would speculate this would also be reflected in RECT. Prendiville et al. (2002) found that rumen temperatures were more highly correlated $(-0.74)$ with ambient temperatures than were RECT $(-0.54)$. Reticular temperatures may be suppressed with warmer ambient conditions because of internal mechanisms to alleviate the effects of heat stress. Cows respond to heat stress by increasing water consumption, reducing feed intake, and reducing VFA production in the rumen (Collier et al., 1982). Such conditions may be conducive to the development of ruminal acidosis. Peripheral vasodilatation may explain some of these differences. As ambient temperatures increase, this process will divert blood flow to the skin of the animal, facilitating transfer of heat into the atmosphere. Because the rectum is a peripheral organ whereas the reticulum is closer to the core of the animal, rectal temperatures may increase more than reticular temperatures during hot conditions. In fact, research in sheep has demonstrated that blood flow to the rumen

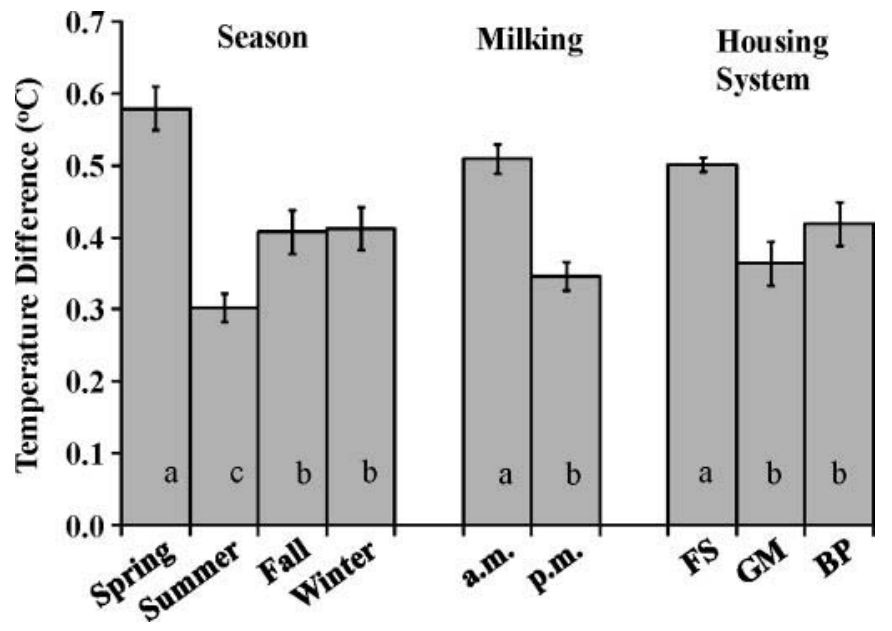

Figure 5. Least squares means for significant fixed effects in mixed models for the difference in reticular and rectal temperature for paired observations (difference calculated by subtracting the rectal temperature from the reticular temperature). Cows were managed in 3 housing systems: a free-stall barn (FS) with 128 stalls in 4 quadrants, a bedded-pack barn with an open grass lot (BP), and a geothermally modified barn with tie stalls for overflow and sick cows and box stalls for recently fresh cows (GM). ${ }^{a-c}$ Least squares means within a category with different letters were significantly different $(P<0.05)$ when using Tukey's adjustment for comparison of means.

epithelium is depressed during heat stress (Hales et al., 1984). Of course, the effect of ambient conditions is not limited to the day of observation; residual effects from conditions before collection may also have influenced recorded temperatures. From these results, it is clear that the variation in TDIF across collection periods is more dependent on changes in RETT than on changes in RECT.

The effects of ambient conditions may be partially masked in this research because both RETT and RECT were collected after milking. Temperatures recorded after milking are reduced because of shade in the holding pen and parlor and by the process of milk removal. Removing milk (which stores heat) from the cow reduces the requirement for heat dissipation to lower body temperature (Araki et al., 1984). Additionally, the holding pen and milking parlor at the Purdue Dairy Research and Education Center is environmentally modified, likely further reducing the temperatures of cows in this study. On the other hand, the holding pen is also the place on the farm where cows likely experience the most heat stress and are less likely to dissipate heat because of their proximity to other cows.

The RETT and RECT for the p.m. milking were significantly greater than for the a.m. milking, although this difference was more pronounced for RECT $(0.30$ vs. $\left.0.12^{\circ} \mathrm{C}\right)$. Greater p.m. temperatures were expected because of diurnal patterns in body temperature, increased ambient temperature during the hours preced- 
ing the p.m. milking, and decreased activity during the hours preceding the a.m. milking. This result signifies that RECT, being closer to the body periphery, are more directly influenced by increasing ambient temperatures through the day. Last, this difference reflects differences in eating or drinking patterns associated with a.m. or p.m. milkings, which would be more likely to influence RETT than RECT. The TDIF was significantly greater for the a.m. milking than for the p.m. milking. This relationship was expected, considering that RECT increased more than RETT for the p.m. milking, essentially closing the gap between the 2 tem-
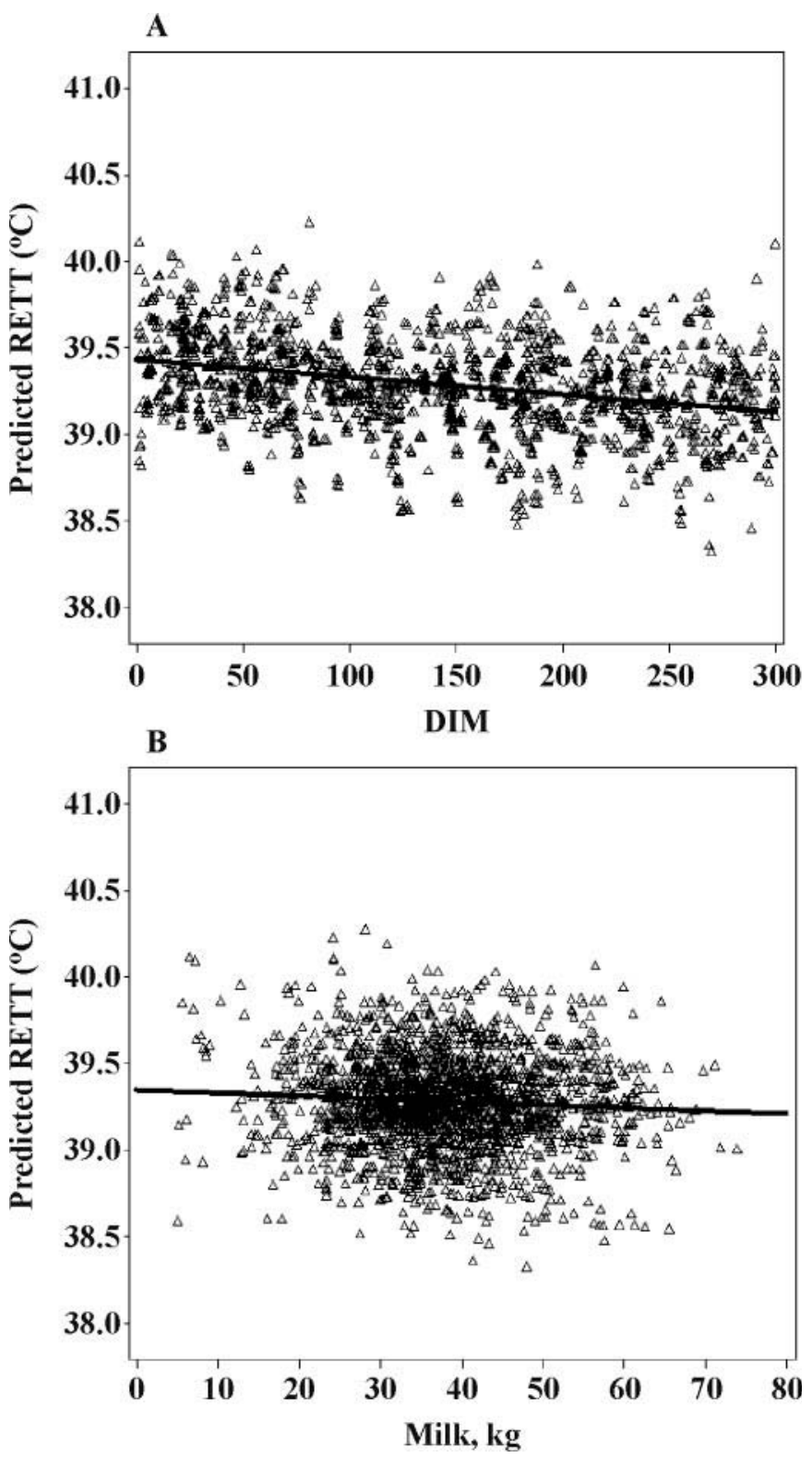

Figure 6. Predicted reticular temperature (RETT) from the mixed model plotted against DIM (a) and milk weight (b). peratures. Correlations between the 2 temperatures were greater in the p.m. than in the a.m., suggesting that the RETT were somehow altered during the a.m. milking. Perhaps increased lying or rumination during the p.m. increased the heat of fermentation in the reticulorumen, resulting in an increase in RETT that was not reflected in RECT. In addition, feed intake may have been lower at night because of reduced feed availability and less frequent push-ups of feed. In turn, digestion and fermentation were likely lower during the night. Metz et al. (1987) demonstrated that body temperature increased by approximately $0.2^{\circ} \mathrm{C}$ while lactating cows were lying indoors (and decreased after standing up); the same pattern was not observed for dry cows on pasture. Consequently, this could increase the a.m. TDIF and decrease the correlation between the 2 temperatures.

These differences are similar to those of Fordham et al. (1988), who reported that vaginal and milk temperatures were 0.16 and $0.23^{\circ} \mathrm{C}$ greater in the p.m. than in the a.m.. Although the literature is consistent with regard to the presence of diurnal variation in temperatures, considerable disagreement exists as to how and when this variation occurs, which is likely attributable to varying ambient conditions and animal or breed characteristics. Wrenn et al. (1961) described 3 different types of diurnal temperature patterns (monophasic, diphasic, and polyphasic) and reported that temperatures were greater in midmorning and evening and low during the evening and early morning hours. Bitman et al. (1984) reported that 4 of 6 lactating cows exhibited diphasic patterns, with high temperatures from midnight to early morning, decreasing temperatures in midmorning, increasing temperatures in the afternoon until evening, and another trough until midnight. Within the day, repetitive patterns of a 0.2 to $0.4^{\circ} \mathrm{C}$ increase followed by a decline in temperature were observed every 80 to $100 \mathrm{~min}$. This pattern was suggested as a control mechanism designed to balance heat production and heat loss within the cow. Lefcourt et al. (1999) found circadian rhythms in 5 of 6 cows with peaks at $2323 \mathrm{~h}$ with an amplitude of $0.34^{\circ} \mathrm{C}$. The diurnal variation of temperatures is affected by feeding, drinking, activity, ambient conditions, and individual animal variation (Bitman et al., 1984). Among housing systems, RETT and RECT were significantly greater for cows in the FS and BP than for cows in the GM. With the cows in the GM in a somewhat controlled environment, RETT and RECT were lower for these cows when compared with the cows in the other 2 housing systems, where conditions were more greatly influenced by changes in the weather.

Based on results from this mixed model, Figure 6 depicts a trend for decreasing RETT with increasing 
A
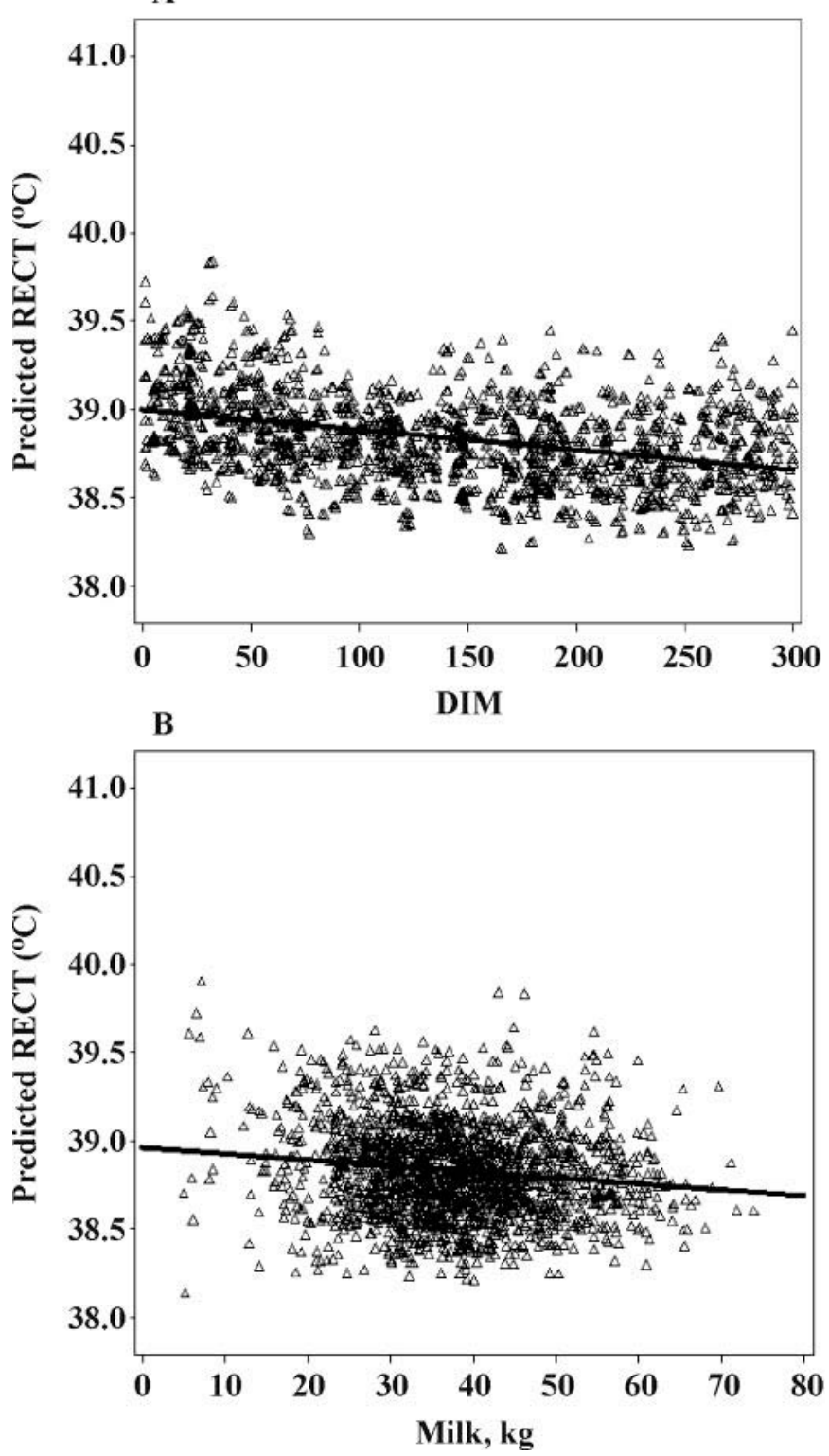

Figure 7. Predicted rectal temperature (RECT) from the mixed model plotted against DIM (a) and milk weight (b).

DIM. Similarly, RETT appeared to decrease with increasing milk yield. In Figure 7, corresponding trends for RECT are demonstrated; however, the relationship for RECT appears to be stronger than for RETT. Metabolic heat production increases with increasing milk production because of increased nutrient metabolism. Araki et al. (1984) also reported greater temperatures for cows in early lactation than in later lactation. Additionally, cows in early lactation were more likely to experience infections or be in estrus, further increasing body temperatures.
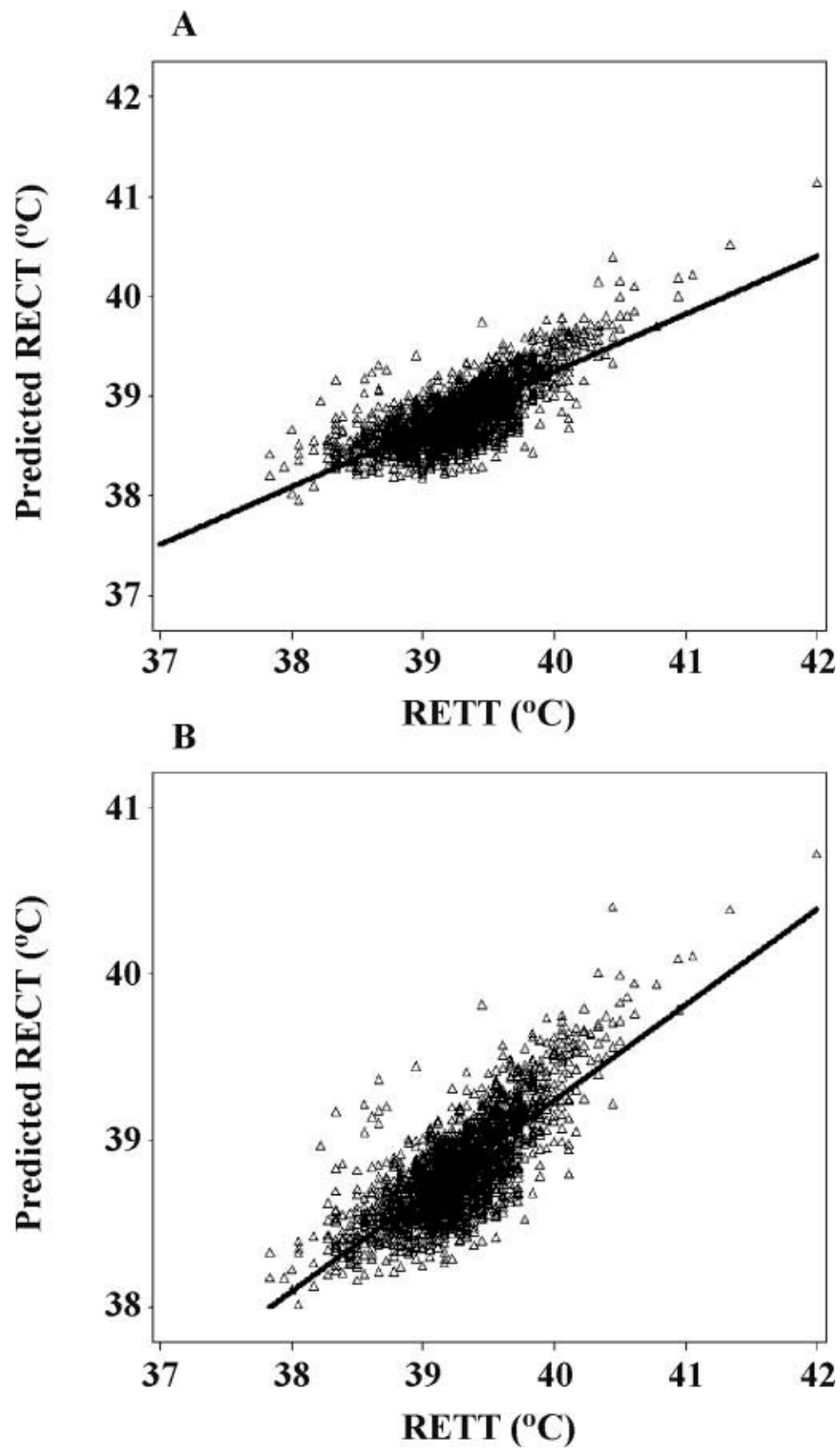

Figure 8. Predicted rectal temperature (RECT) versus actual reticular temperature (RETT) for the conversion model (a) and the full mixed model (b).

\section{Conversion Equations}

A secondary objective of this work was to develop an equation for converting a RETT- to a RECT-based scale. Two separate mixed models were fit to describe RECT by using RETT (Table 4). The full model included all significant fixed effects for prediction of RECT along with associated interactions. Significant fixed effects in this model included RETT, milking, housing system, season, and parity, either through main effects or within interaction terms. The conversion equation model included only RETT and milking because these were the only variables likely to translate to conditions on other farms using this technology. The 
Table 4. Model parameters and $P$-values for fixed effects for mixed models describing rectal temperatures using reticular temperatures

\begin{tabular}{|c|c|c|}
\hline Item & $\begin{array}{c}\text { Conversion } \\
\text { equation model }\end{array}$ & Full model \\
\hline Observations, $\mathrm{n}$ & 2,042 & 2,033 \\
\hline Akaike's information criterion & -346.9 & 27.2 \\
\hline Schwarz's Bayesian criterion & -337.9 & 36.2 \\
\hline \multicolumn{3}{|l|}{ Fixed effect } \\
\hline Intercept & $<0.0001$ & 0.1264 \\
\hline Reticular temperature & $<0.0001$ & $<0.0001$ \\
\hline Milking & $<0.0001$ & 0.0690 \\
\hline Reticular temperature $\times$ milking & $<0.0001$ & 0.0414 \\
\hline Season & & 0.0007 \\
\hline Housing system & & 0.0100 \\
\hline Parity & & 0.9434 \\
\hline DIM & & 0.0152 \\
\hline Milk weight & & 0.2083 \\
\hline Season $\times$ parity & & 0.0094 \\
\hline Housing system $\times$ parity & & 0.2112 \\
\hline Milking $\times$ parity & & 0.0319 \\
\hline $\mathrm{DIM} \times$ parity & & 0.0783 \\
\hline DIM $\times$ housing system & & 0.0563 \\
\hline DIM $\times$ milking & & 0.5573 \\
\hline Milk weight $\times$ season & & 0.1781 \\
\hline Milk weight $\times$ parity & & 0.0341 \\
\hline DIM $\times$ milk weight & & 0.0004 \\
\hline Reticular temperature $\times$ season & & 0.0007 \\
\hline Season $\times$ milking & & 0.0063 \\
\hline Season $\times$ housing system & & $<0.0001$ \\
\hline Milking $\times$ housing system & & $<0.0001$ \\
\hline Reticular temperature $\times$ parity & & 0.9387 \\
\hline Reticular temperature $\times$ housing system & & 0.0088 \\
\hline Reticular temperature $\times$ DIM & & 0.0176 \\
\hline Reticular temperature $\times$ milk weight & & 0.2159 \\
\hline Reticular temperature $\times$ milking & & 0.0414 \\
\hline Season $\times$ housing system $\times$ parity & & 0.0240 \\
\hline Milking $\times$ season $\times$ parity & & 0.0253 \\
\hline DIM $\times$ season $\times$ parity & & 0.0669 \\
\hline DIM $\times$ season $\times$ housing system & & 0.0811 \\
\hline DIM $\times$ milking $\times$ season & & 0.0528 \\
\hline DIM $\times$ milk weight $\times$ season & & 0.0427 \\
\hline DIM $\times$ milk weight $\times$ parity & & 0.0237 \\
\hline Reticular temperature $\times$ season $\times$ parity & & 0.0098 \\
\hline Reticular temperature $\times$ season $\times$ housing system & & $<0.0001$ \\
\hline Season $\times$ milking $\times$ reticular temperature & & 0.0060 \\
\hline $\mathrm{DIM} \times$ reticular temperature $\times$ season & & $<0.0001$ \\
\hline DIM $\times$ milk weight $\times$ reticular temperature & & 0.0004 \\
\hline
\end{tabular}

resulting conversion equations were $\mathrm{RECT}=19.23+$ 0.496(RETT) for the a.m. milking and RECT $=15.88$ +0.587 (RETT) for the p.m. milking. These equations take into consideration the relationship between RETT and RECT and account for the diurnal fluctuation in this relationship along with core body temperature in general.

Figure 8 depicts the strong relationship between RETT and predicted RECT when using these mixed models. Both the simple conversion model and the full model appear to do an adequate job of converting RETT to a scale more reflective of one more familiar to the RECT producers and veterinarians. These equations may be used by producers using the Phase IV CTMS on farm or other technologies measuring RETT.
They may prove useful for interpreting temperatures provided by such systems by producers and veterinarians. Further, the results will help in interpreting research results from reports using RETT.

\section{CONCLUSIONS}

Collected RETT and RECT were influenced by season, milking, housing system, and parity. Both locations were subject to more measurement error and variation than anticipated. The RETT were greatly correlated with RECT, demonstrating that RETT provided a reasonable estimate of core body temperature in dairy cattle. The relationship between RETT and RECT varied by season, milking, housing system, and par- 
ity. The dynamics of the reticulorumen environment, particularly related to feed and water intake, likely influenced this relationship and could affect the utility of RETT in an automated temperature-monitoring system. Nevertheless, these results are encouraging for the use of newly available technologies for monitoring RETT. Additional research is needed to evaluate the feasibility of these technologies for identifying physiological events of interest.

\section{ACKNOWLEDGMENTS}

The authors acknowledge the staff of the Purdue Dairy Research and Education Center and a series of student workers for their assistance in data collection. Len Wallace (MaGiiX Inc.) is also recognized for his financial contributions to this project and ongoing work at the Purdue Dairy Research and Education Center.

\section{REFERENCES}

Aalseth, E. 2005. Fresh cow management: What is important, what does it cost, and what does it return? Pages 1-12 in Proc. 7th Western Dairy Manage. Conf., Reno, NV.

Araki, C. T., R. M. Nakamura, L. W. G. Kam, and N. Clarke. 1984 Effect of lactation on diurnal temperature patterns of dairy cattle in hot environments. J. Dairy Sci. 67:1752-1760.

Bewley, J. M., D. C. Batson, M. W. Grott, and M. M. Schutz. 2007. Impact of intake water temperatures on reticular temperatures of lactating dairy cows. J. Dairy Sci. 91:3880-3888.

Bitman, J., A. Lefcourt, D. L. Wood, and B. Stroud. 1984. Circadian and ultradian temperature rhythms of lactating dairy cows. J. Dairy Sci. 67:1014-1023.

Burns, P. D., W. R. Wailes, and P. B. Baker. 2002. Changes in reticular and rectal temperature during the periestrous period in cows. J. Anim. Sci. 80(Suppl. 2):128.

Collier, R. J., D. K. Beede, W. W. Thatcher, L. A. Israel, and C. J. Wilcox. 1982. Influences of environment and its modification on dairy animal health and production. J. Dairy Sci. 65:2213-2227.

Firk, R., E. Stamer, W. Junge, and J. Krieter. 2002. Automation of oestrus detection in dairy cows: A review. Livest. Prod. Sci. $75: 219-232$.
Fordham, D. P., P. Rowlinson, and T. T. McCarthy. 1988. Oestrus detection in dairy cows by milk temperature measurement. Res. Vet. Sci. 44:366-374.

Gengler, W. R., F. A. Martz, H. D. Johnson, G. F. Krause, and L. Hahn. 1970. Effect of temperature on food and water intake and rumen fermentation. J. Dairy Sci. 53:434-437.

Hahn, G. L., R. A. Eigenberg, J. A. Nienaber, and E. T. Littledike. 1990. Measuring physiological responses of animals to environmental stressors using a microcomputer-based portable datalogger. J. Anim. Sci. 68:2658-2665.

Hales, J. R. S., A. W. Bell, A. A. Fawcett, and R. B. King. 1984 Redistribution of cardiac output and skin AVA activity in sheep during exercise and heat stress. J. Therm. Biol. 9:113-116.

Hicks, L. C., W. S. Hicks, R. A. Bucklin, J. K. Shearer, D. R. Bray, P. Soto, and V. Carvalho. 2001. Comparison of methods of measuring deep body temperature of dairy cows. Pages $432-438$ in 6th Int. Symp. ASAE, Louisville, KY. Am. Soc. Agric. Biol. Eng., St. Joseph, MI.

Lefcourt, A. M., J. B. Huntington, R. M. Akers, D. L. Wood, and J. Bitman. 1999. Circadian and ultradian rhythms of body temperature and peripheral concentrations of insulin and nitrogen in lactating dairy cows. Domest. Anim. Endocrinol. 16:41-55.

McVicker, L. E., M. J. Leonard, and D. E. Spiers. 2001. Evaluation of feedlot cattle response to summer heat in open or shaded pens. Pages 104-107 in 15th Conf. Biometeorol./Aerobiol. and 16th Int. Congr. Biometeorol.

Metz, J., F. Wiersma, W. Rossing, and V. Van Den Berg. 1987. First experiences with a telemetry system for measurements of body temperature by dairy cows. Pages 185-197 in 3rd Symp. Automation in Dairying, Wageningen, the Netherlands. IMAG, Wageningen, the Netherlands.

National Oceanic and Atmospheric Administration. 1976. Livestock hot weather stress. US Dept. Commerce, Natl. Weather Serv. Central Reg. Operations Manual Lett. C31-76. Natl. Oceanic Atmospheric Admin., Kansas City, MO.

Noffsinger, T. L., K. K. Otagaki, and C. T. Furukawa. 1961. Effect of feed and water intake on rumen and body temperatures of sheep under subtropical conditions. J. Anim. Sci. 20:718-722.

Prendiville, D. J., J. Lowe, B. Earley, C. Spahr, and P. Kettlewell. 2002. Radiotelemetry systems for measuring body temperature. Beef Prod. Ser. No. 57. Grange Research Centre, Tunsany, UK.

Sievers, A. K., N. B. Kristensen, H.-J. Laue, and S. Wolffram. 2004 Development of an intraruminal device for data sampling and transmission. J. Anim. Feed Sci. 13(Suppl. 1):207-210.

Wrenn, T. R., J. Bitman, and J. F. Sykes. 1961. Diurnal patterns of bovine body temperature. J. Dairy Sci. 44:2077-2080. 